\title{
A New Look at Atherosclerosis Repeatable Science Ushers in a New Era of Medicine
}

\section{Introduction}

Clinicians are now able to prevent and reverse coronary artery disease using non-invasive, inexpensive and nontoxic interventions, while monitoring progress serially in an inexpensive, non-invasive, non-toxic manner. This results in a reduction of heart attack and stroke by 98 percent, not to mention the many other complications of atherosclerosis. The science behind this is not new and, in fact, coronary artery disease, noted by coronary atherosclerosis or cholesterol plaque build-up in these arteries, was first shown to be reversible in humans as early as 1954. This study was published in the peer-reviewed medical literature [1].

The study, by Dr. Willis was remarkable and well ahead of its time. He was able to show the progression or regression of atherosclerosis in living humans for the very first time, using an innovative idea of injecting radio-opaque dye into the vessels and taking x-rays of the arteries in a serial manner. He did this before and after his proposed intervention.

Another item of note in Willis' study was his showing that in patients with atherosclerosis as demonstrated on serial arteriography, these plaques were able to reverse using nutrient supplementation in a non-toxic, non-invasive, inexpensive program. In fact, in his preliminary work into the reversal of coronary artery disease in humans, he was able to demonstrate that 60 percent of study participants had a reversal, or improvement, in what, up until now, has been thought to be a progressive and irreversible necessity of degeneration. The intervention was Vitamin C taken orally in a dose of $500 \mathrm{mg}$ three times per day. This dose was chosen based on earlier studies and was designed to maintain a steady tissue concentration of Vitamin C.

In 1955, Willis et al. [2] did a study based on autopsies that showed a focal deficiency of Vitamin C in the coronary arteries of patients who had died of suddenly [2]. In some instances, they found that the tissue concentration of Vitamin C in the aorta was seriously depleted despite being in a normal, well-nourished previously healthy individual. This tended to be exacerbated by advancing age and areas of mechanical stress, as described by Virchow [3], who showed that atherosclerosis occurs at particular high pressure points in the vascular system. Combining the two observations, he reasoned that intimal damage in the vessel resulted from increases in pressure in the absence of Vitamin C's protective effect to the ground substance.

Our current understanding of atheroma formation, leading to atherosclerosis of the coronary arteries, and many other arteries, recognizes that as plaques build, they become less stable [4-10]. When these unstable plaques fracture off, they cause an environment that is chemically favorable to thrombosis. They also can become emboli or create thromboemboli. These thromboses and emboli lead often to sudden vascular events or phenomena

Review Article
Volume 9 Issue 5 - 2017
Sam Wallace $1 *$ and Wallace ${ }^{2}$
${ }^{1}$ Missoula Osteopathic Clinic, USA
${ }^{2}$ Diploma of CardioRetinometry, USA
*Corresponding author: Sam Wallace, Missoula Osteopathic
Clinic, Montana 59802, USA
Received: September 21, 2017 | Published: September 29,
2017

such as heart attack, stroke, central retinal artery occlusion, mesenteric infarction and many other problems. It stands to reason, and it is the currently acceptable approach, to stabilize these plaques in order to prevent these events [11,12]. It is now being shown that the best way to do this is through non-invasive, inexpensive, non-pharmacological nutrient supplementation as has been demonstrated by Willis, Pauling, Rath and Bush [1,1315]. Willis' landmark work received no attention until later when Linus Pauling and Matthias Rath, MD, a cardiologist, did experiments that confirmed the work of Dr. Willis.

Willis, Pauling and Rath all believed that atherosclerotic plaques were a part of the healing process of the arteries due to a chronic and focal ascorbutic condition (scurvy). Bush's work, able to repeated here, has confirmed this. Willis had already demonstrated in autopsies that a local tissue depletion of Vitamin C often occurred (focal scurvy) in patients who did not show signs of acute scurvy (low grade chronic scurvy). Pauling and Rath tested guinea pigs given a scorbutic diet and found that Lp(a), or Lipoprotein alpha, was raised in guinea pigs not receiving Vitamin C but not in those receiving it $[16,17]$. This $L p(a)$, they theorized, a sticky, low density lipoprotein with multiple lysine binding sites, was responsible for invading the intima of the artery and producing atherosclerosis. Using $40 \mathrm{mg} / \mathrm{kg} /$ day of Vitamin C was able to prevent the formation of plaque and the rise in $\mathrm{Lp}(\mathrm{a})$. They suggested that a similar mechanism would exist in humans due to the similarities in the formation of atherosclerosis and the rise of Lp(a) in humans and guinea pigs.

Robert Hollenhorst noted in 1961 that streaks of bright white or yellow in the vessels of the retina and visible on fundoscopic exam or photograph, were not a normal reflexive light refraction as previously thought, but instead a collection plaque development, atheroma and fatty emobi, representing an extent 
of atherosclerosis that was easily visible on these exams [18] Dr. Sydney Bush, founder of the science of CardioRetinometry ${ }^{\circledR}$, noted in 1999 that these 'light reflexes' were disappearing from the retinal vessels of patients receiving Vitamin $C$ for irritation from their contact lenses. Since he had been taught that these atheromas were normal findings, he did not at first understand what he was seeing. On subsequent research, he found that, although not taught, it was demonstrated decades before by Hollenhorst that these were not normal findings at all [18].

Dr. Bush has since been following patients for eighhteen years and has noted a consistent ability to reverse fundoscopic vessel atherosclerosis while improving patients' overall cardiovascular status and function [18]. These results are very predictable and a new terminology has been created to discuss and describe these previously unwitnessed events (Figure 1). In 1979, Michelson et al. [19] studied how these findings relate to coronary artery disease [19]. Their findings were published in the Archives of Internal Medicine. Each coronary vessel was graded with respect to its most occlusive lesion by angiography; coronary index was derived for each patient without knowledge of eye findings. Abnormal light reflex changes were the most sensitive indicators of presence and extent of coronary artery disease. Abnormal vessel tortuosity and decreased caliber were less sensitive but more specific; their presence also suggested more extensive coronary lesions. These studies were repeated by TedeschiReiner et al. [20] in 2005and published in the American Journal of Cardiology. They found a nearly one-hundred percent correlation between fundoscopic vessel atherosclerosis and coronary artery disease.

Dr. Bush was able to fuse the work of these doctors and his own unique observation to develop CardioRetinometry ${ }^{\circledR}$ whereby the practitioner uses serial monitoring of the retinal vessels and administers the Pauling/Rath therapy along with other vital and non-toxic nutrients in order to stabilise, reverse and eliminate atherosclerosis in the retinal vessels, the coronary arteries and throughout the rest of the body. This stabilisation results in a vastly decreased potential for a vascular event to where Rath states, "No heart attack would occur." While Bush mostly agrees, it is understood that not all myocardial infarctions are thrombotic in nature, but that it would be most unlikely to have an event from the fracture of an unstable plaque, decreasing the chance of heart attack or stroke by 98 percent. However, Bush cautions that while plaque is regressing, coronary artery spasm may occur and thrombosis is not the only mechanism of heart attack. This greatly reduces mortality and morbidity associated with these devastating illnesses, as well as many other problems that atherosclerosis causes [19,21,22].

The approach is non-invasive, inexpensive, non-toxic and has no serious side effects. The monitoring is practically as effective as the current gold standard of angiogram but at a small fraction of the price and without harmful radiation. The ease, cost, safety and effectiveness of CardioRetinometry ${ }^{\circledR}$ for the prevention and reversal of coronary artery disease, stroke and other complications of atherosclerosis greatly improve upon conventional therapy and beckon in a new science and a new era of medicine (Figure 2). Most mammals produce their own Vitamin $C$ in an enzymatic pathway that converts glucose to ascorbic acid. This is a 10-step biochemical process. These mammals produce Vitamin C in boluses as needed continuously throughout their lives, with the dose increasing depending on stressors placed on the animal. A daily dose for an animal can range normally between the human equivalent of 5,000 to $15,000 \mathrm{mg}$ per day [23].

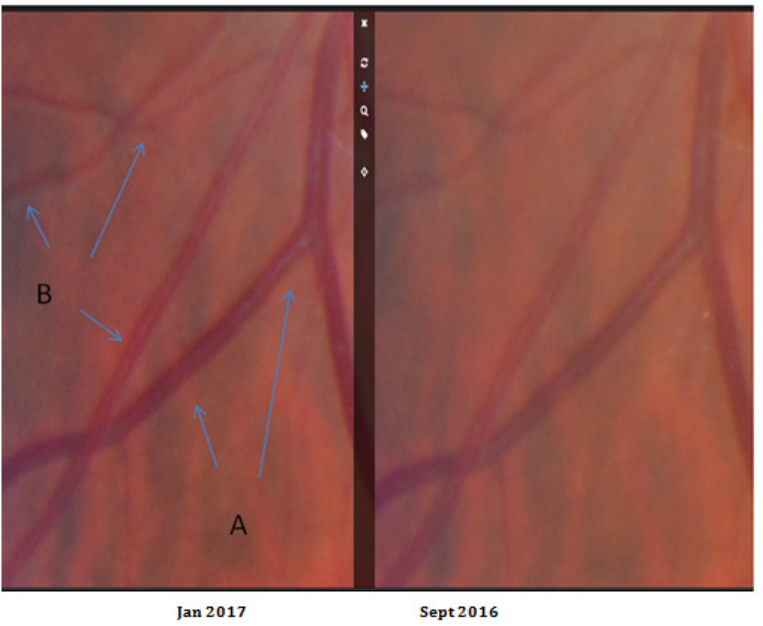

Figure 1: Retinal image before and after four months of therapy on Vitamin C, lysine and proline. The image on the right was taken in September of 2016. The image on the left was taken in January of 2017, four months later. This was done by the author of this article, in the United States, under the tutorship of Dr. Bush in Spain. Note on the left both the wider darker vessels, the venules and the narrower vessel, the arteriole show increased patency and decreased atherosclerosis throughout. The two arterioles in the upper left of each image have increased patency as well. The plaque at the bifurcation of the venule has decreased overall mass. Early improvements may be seen in a relatively short time. These images confirm what Dr. Bush has stated with regard to the potential of CardioRetinometry ${ }^{\circledR}$ and shown the work to be repeatable.

Please note: The venous system forms atherosclerosis. See it here and its reversal. Perhaps this will contribute to the understanding of deep venous thrombosis, varicose veins, pulmonary hypertension and other diseases of veins.

A number of mammals, however, do not have the ability to do this. These include the fruit bat, guinea pigs and primates, including humans. In all these mammals, the biochemical pathway to make Vitamin C is present but has one or another defect. In humans, there is genetic point mutation that affects the enzyme in the last of ten steps. Glucose can be taken 90 percent of the way to Vitamin C [24]. The enzyme in the final step needs to be shaped like a hand to catalyze the final step but the point mutation makes the fingers bend backwards resulting in a totally defunct enzyme. Thus, humans cannot form the effective vital nutrient ascorbic acid [24]. One theory on this is that a genetic mutation took place during the evolution of human ancestors about forty million years ago, but was not fatal as this occurred when said ancestors were living equatorially and subsisting mostly on fruit, high in Vitamin C [25]. Such mammals have developed a number of compensatory mechanisms for their lack of ability to form Vitamin C. One of these mechanisms is atherosclerosis itself [26]. The mammals 
that produce their own Vitamin C do not form atherosclerosis under natural circumstances [23]. Yet the deficient mammals will develop atherosclerosis on a scorbutic diet [27].

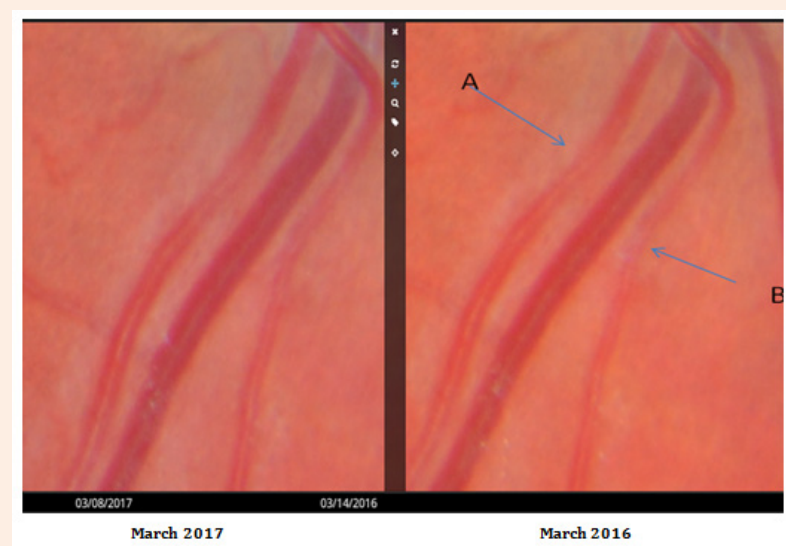

Figure 2: Retinal images after one year of Vitamin C, lysine and proline.

This image demonstrates some of the unique advantages of CardioRetinometry®.

Point A and B on the right image show an appearance of total occlusion in these retinal arterioles. The image on the left shows a very early improvement. A trained practitioner of CardioRetinometry ${ }^{\circledR}$ will note that the vessels on the same points on the left are beginning to show margins around the plaque, or increased patency. This is positive; however, there is a problem. After a year of therapy, this improvement is not as much as would be expected. This would spur a search for a cause: Noncompliance, increased oxidative stress from unknown factor: Silent infection (tooth abscess, chronic sinusitis, many others), stressful life changes (divorce, death of a loved one, elder care, many others).

In this case the patient was confused on the dosing and was taking onefourth the recommended dose. CardioRetinometry® can identify and initiate a search for cause and effect. This allows proper intervention years or decades before an event occurs. No other method of visualization can currently hope to achieve this degree of magnification and direct visualization of atherosclerotic plaque and achieve this titration of therapy or differential diagnosis.

In humans, several other specific mechanisms seem to have evolved that delay the onset and progression of atherosclerosis but are not sufficient to stop it entirely, perhaps as evidenced by its being the number-one killer in the world [28,29]. One of these compensatory mechanisms is $\operatorname{Lp}(\mathrm{a})$. This mechanism also is present in guinea pigs as per Pauling and Rath's experiment in 1990 [16]. They theorized that this is a surrogate for repair of the vessel in the absence of adequate Vitamin C, and proved this to be true in the study mentioned above.

A second compensatory mechanism is the human ability to recharge spent Vitamin $\mathrm{C}$, to recycle it but reducing it in the red blood cells. This Erythrocytic Recycling can apparently revitalize the body's entire store of Vitamin C in as little as three minutes [28]. This may be why the progression of atherosclerosis in humans with inadequate Vitamin $\mathrm{C}$ takes decades as opposed to months with guinea pigs $[30,31]$. There is some discussion that intestinal flora in humans may symbiotically produce Vitamin $\mathrm{C}$ that can be used by the human host [32]. This may be one potential explanation as to why some individuals do not seem to develop atherosclerosis as quickly as others.

Vitamin C is a vital nutrient and is important to form the most abundant protein in the structure of the human body, collagen [33]. Collagen gives structural integrity to most body tissues including the basement membrane of the arterial intima as well as the ground substance that supports the endothelial lining [34]. It would seem, based on Willis' work and autopsies of patients who had died suddenly of trauma versus those that had died of heart disease, that a focal tissue depletion of Vitamin C can occur and lead to a rationing effect of Vitamin $\mathrm{C}$, where some tissues are getting the bulk of the inadequate share of Vitamin $\mathrm{C}$ and seeming healthy and normal while other tissues suffer a focal scurvy and structural degradation [35]. This seems to occur in the white blood cells since they have cell membrane pumps that take up 35 times the amount of Vitamin C than other cells. This allows them to perform their various immune and phagocytic functions. White blood cells can show a normal level of Vitamin C despite an overall deficiency in the body in general or certain tissues in specific, the arteries being a common site of tissue depletion of Vitamin C [36].

It is felt that this focal deficiency can be overcome with:

a) Adequate intake of Vitamin $\mathrm{C}$

b) Decreased oxidative exposure that depletes Vitamin C

\section{Adequate intake of Vitamin C}

The Recommended Dietary Allowance (RDA) for Vitamin C is currently set at $90 \mathrm{mg}$ per day for adults [37]. This level was determined by the FDA and is based on measuring saturation of the white blood cells of the body. As previously mentioned, the white blood cells can pump Vitamin C into their cells and are one of the last tissues to suffer from a global Vitamin C deficiency. They are quickly replenished when Vitamin $C$ is replaced in even small doses [36]. Acute scurvy does not occur with as little as 10 $\mathrm{mg}$ of Vitamin C. Willis' study would seem to indicate that $500 \mathrm{mg}$ of oral Vitamin C three times a day could be highly beneficial to slightly over half the population studied [1].

Rath suggested $600 \mathrm{mg}$ to $3,000 \mathrm{mg}$ per day for general health [38]. Pauling recommended $6,000 \mathrm{mg}$ to $18,000 \mathrm{mg}$ [39]. Levy recommended $3,000 \mathrm{mg}$ to $9,000 \mathrm{mg}$ per day [40]. Rath was able to demonstrate the reversal of coronary atherosclerosis with visualisation by ultra-fast coronary artery CT scan [41]. Dr. Bush has seen results with doses up to 20,000 mg per day. Authors and scientists Hickey and Roberts believe that the RDA needs to be reevaluated in light of the fact that a focal chronic scurvy can occur and lead to atherosclerosis and other problems as has been shown in multiple studies [42].

Numerous studies have also been done and published in peer-reviewed medical literature. In many of them, doses of Vitamin C have been used in excess 5,000 mg per day. Doctors treating patients with high doses of Vitamin C, up to 10,000 mg per day and more, have reported only improvements in patients [43-45]. High doses of IV Vitamin C have been given in clinical trials and found to be well-tolerated without significant side effects and showing no adverse reactions [46]. This is consistent with Ewing Cameron's observation of terminal cancer patients 
receiving doses of up to $10,000 \mathrm{mg}$ of Vitamin C [47]. Klenner used Vitamin C injections and IVs in doses of 2,000 mg every four hours for problems from polio to snake envenomation showing it to be well-tolerated by patients and effective as an anti-viral, anti-toxin and anti-oxidant. He published several studies in peerreviewed literature and outlined his results in a book about his use of Vitamin C [43-45,48,49]. Notably, prior to the Salk Vaccine for polio, Klenner had 60 out of 60 cases of polio that were cured without any neurological sequelae using Vitamin $C$ in such a dose. He reported no adverse events from this.

For these and many other reasons, noted in authors Hickey and Roberts' book, the RDA for Vitamin C is likely set at a level to prevent only acute scurvy and not provide many other benefits that Vitamin C has been proven to have. Dr. Bush had noted over several decades that the individual requirement for Vitamin $\mathrm{C}$ can change and vary quite dramatically based on multiple factors [50], all of which affect oxidative stress in the body, including but not limited to:

a) Infection

b) Emotional Trauma

c) Physical Trauma

d) Dietary Changes

e) Depression/Anxiety

f) Dental procedures

g) Medication use

h) Life stressors

i) Season changes

j) Hydration

k) Timing versus last ingested Vitamin C

l) Time of day

m) Time of year

n) Inflammation

o) Gender

p) Age

q) Diabetes

r) Hypertension

s) Heavy Metal Exposure

t) Deficiencies of vitamins and/or minerals

These observations are consistent with the multiple-studied causes of oxidative stress leading to Vitamin C deficiency that have been published in peer-reviewed medical literature, as documented by Dr. Thomas Levy, JD, MD, a cardiologist. Levy has written several books, including his landmark review of the pertinent peer-reviewed literature on the oxidative stress effect on Vitamin C levels and coronary atherosclerosis [51]. He cites more than 650 peer-reviewed studies on the subject in this comprehensive work. This fluctuating need for Vitamin C may also explain why Willis saw improvement in just over half of the human subjects in his study. It also underscores the importance of not just estimating what an adequate dose of therapy may be for any particular patient, though this would be better than nothing. The stakes of coronary atherosclerosis are too high and the therapy easily accessible.

The mechanism of action of Vitamin $\mathrm{C}$ in the prevention and reversal of atherosclerosis is at least two-fold. First, Vitamin $\mathrm{C}$ neutralizes free radicals that are known to damage the endothelium. It does this by carrying two loose electrons that it can easily donate [52]. Because of the loosely-held electrons, Vitamin C is stable whether it has one or two electrons available. This is in sharp contrast to the free radical molecule that has one very unstable electron. Its electron will react indiscriminately with any tissue it contacts, damaging that tissue. The endothelium is quite susceptible to damage of free radicals that circulate in the blood stream. Should plasma and tissue concentration of Vitamin $\mathrm{C}$ be adequate, then when said free radical comes into the tissue, the Vitamin C neutralizes the damaging effect by easily donating an electron, becoming oxidized itself but remaining stable, so as to not cascade the free-radical damage.

The other mechanism is by providing the required material for the formation of collagen, which allows the vessel to heal. When a vessel is damaged, cholesterol, specifically Lp(a) adheres to the exposed amino acids beneath the endothelial lining. This serves as a patch to keep the vascular channel viscous and moving. Once the vessel heals, the cholesterol patch can reabsorb from the vessel wall, thus reversing atherosclerosis and repairing the vessel. These changes are clearly evident in the studies by Willis et al., Pauling and Rath and in images taken and evaluated with CardioRetinometry ${ }^{\circledR}$ on numerous patients by Bush.

\section{Misconceptions about Vitamin C}

For various reasons, there are a great number of misconceptions that are perpetuated through the medical field. Thomas Levy, JD, MD has outlined these in his book Primal Panacea [53]. They are worth reiterating here:

A) There are no studies on Vitamin C

A Pub Med search today yields 58,612 studies on Vitamin C. Many of these studies show a positive effect with regard to a number of illnesses, as one might expect from an antioxidant and precursor to the most abundant protein in the body, whose total absence causes a painful and rapid death and whose relative deficiency has been proven to be the world's deadliest condition.

\section{B) There is no evidence that Vitamin C works}

Again, Vitamin C, per the literature, appears to work for just about everything and is necessary for life itself. Many studies have shown it to be effective in many ailments. Only a fraction of them is even possible to outline. Levy referenced 1,200 studies on Vitamin C in peer-reviewed literature almost all showing a beneficial effect. This massive undertaking of his still only scratches the surface about what is known about the benefits of Vitamin C. 


\section{C) Vitamin C is not safe}

Dr. Levy points out that no lethal dose has ever been found for Vitamin C, even though many clinicians have used doses routinely of 250,000 to $300,000 \mathrm{mg}$ daily (about 3,300 times the RDA) with no reported side effects. He points to a study that shows that water is more toxic than Vitamin C. He does not miss the irony that while Vitamin $C$ exhibits an astonishing safety profile, pharmaceutical medications kill more than 100,000 patients per year in hospitals alone, yet are considered safe and effective. Dr. Cathcart treated more than 20,000 patients in twenty-years with no incidence of major side effects from doses around 15,000 to $200,000 \mathrm{mg}$ of Vitamin C per day. ${ }^{60}$ It should not be too much of a leap to state that it is unsafe not to reverse heart disease. On balance, it would appear from the evidence that it is much safer to take enough Vitamin $\mathrm{C}$ than to take less than that, and it has been shown harmless to take more.

\section{D) Vitamin C causes kidney stones}

No study has demonstrated this. A study of 85,557 women followed for fourteen years found no association between Vitamin $C$ intake and kidney stone formations. Another study found that Vitamin C lowered the incidence of kidney stones.

E) Dietary intake of Vitamin C is adequate

The question is what exactly is dietary intake adequate for? To prevent acute scurvy, then yes, it is. To prevent and reverse atherosclerosis in 60 percent or greater of the population, then no, it is not.

Willis et al. reversed atherosclerosis, the number-one killer, with $500 \mathrm{mg}$ of Vitamin C three times per day, or a total of 1,500 mg per day. A person would have to eat fifteen red peppers per day, or twenty-two oranges per day to achieve these levels. And that was only enough Vitamin $C$ to reverse atherosclerosis in 60 percent. Dr. Bush has found he had to use much higher levels to observe the reversal of atheroma using CardioRetinometry®, sometimes in excess of 10,000 mg per day (105 red peppers, 142 oranges) [54]. Since it is proven to reverse atherosclerosis and is harmless, it is imperative that it is used as such. Thus, dietary intake is not adequate to achieve these important outcomes.

F) When people take high doses of Vitamin C, they simply lose it in their urine without benefit

To say that Vitamin C is without benefit simply because it is excreted in the urine would be similar to saying we don't need water since it is excreted in the urine. While water is excreted in the urine, it performs many vital functions in the body beforehand. Vitamin C is water soluble and is excreted in the urine, but as we can see from virtually any study we look at, it performs many valuable functions prior to doing so. We also have conclusive evidence that it reverses atherosclerosis prior to being excreted in the urine.

I) If it works so well, everybody would be using it

It works; start using it. Several studies show it to reverse atherosclerosis, the precursor to heart disease and stroke and a multitude of other deadly, debilitating, painful, disfiguring conditions. Now that we have the ability to take guesswork out of the dosing with easily obtainable serially retinal images and can prove effectiveness on a case-by-case basis, there is no reason not to.

\section{Current approach to treatment and prevention of heart disease:}

Our current approach to the prevention of heart disease focuses on the treatment of hypertension, hypercholesterolemia and aspirin use. Multiple randomized clinical trials have been run on these treatments that have shown an effect in mortality with heart disease and stroke [55]. These findings have been presented as medical imperatives to treat due to the statistically significant decreases in the incidence of heart attack, stroke and increased mortality. The rates of improvement have all been stated in terms of relative risk reduction. These statistics inevitably exaggerate the actual benefit of these medications. Looking at the statistical analysis of absolute risk gives a better idea of how these treatments are actually going to help the patients. Some of these standard of care treatments are listed below [56]:

Use of Antihypertensives to treat mild hypertension:

NNT: None was helped by this therapy

NNH: One in twelve was harmed (8.3 percent)

i. Use of Antihypertensives to prevent heart attack, stroke and death:

ii. One in 125 was helped (prevented death) (0.8 percent)

iii. One in 67 was helped (prevented stroke) (1.5 percent)

iv. One in 100 was helped (prevented heart attack) (1percent) NNH: One in 10 was harmed. (10 percent)

Aspirin to prevent first heart attack or stroke:

i. One in 1,667 was helped (cardiovascular problem prevented)

ii. None was helped (prevented death)

iii. One in 2,000 was helped (prevented non-fatal heart attack)

iv. One in 3,000 was helped (prevented non-fatal stroke)

NNH: One in 3,333 (major bleeding event)

Aspirin for secondary prevention of heart attack or stroke:

i. One in 50 was helped (cardiovascular problem prevented)

ii. One in 333 was helped (prevented death)

iii. One in 77 was helped (prevented non-fatal heart attack)

iv. One in 200 was helped (prevented non-fatal stroke)

NNH: One in 400 (major bleeding event)

Aspirin for survival of major heart attack:

i. One in 42 was helped (life saved at one month) 
NNH: One in 167 (bleeding to point anemic but not transfused)

Beta blockers for heart attack:

i. None was helped

NNH: One in 91 (Cardiogenic shock)

Statins for five years with no known heart disease:

i. None was helped (life saved)

ii. One in 60 was helped (preventing heart attack)

iii. One in 268 was helped (preventing stroke)

NNH: One in 50 (developed diabetes)

One in ten (muscle damage)

Statins for five years with prior heart disease:

i. One in 83 was helped (life saved) (1.2 percent)

ii. One in 39 was helped (preventing non-fatal heart attack) (2.5 percent)

iii. One in 125 was helped (preventing stroke) ( 0.8 percent)

NNH One in 50 (developed diabetes) (2 percent)

One in ten (muscle damage) (10 percent)

Statins for acute coronary syndrome:

i. None was helped

\section{NNH: Unknown}

In light of these numbers, there is much to be desired in an effective solution to atherosclerosis, heart attack and stroke. As for the benefit of combined therapy with these medications, there is no data. For all that is known, combined therapy may worsen mortality. The studies had to have a large number of participants to have enough power to show these small effects. Overall, the most powerful effect from the medications listed above would be that they help 2.5 percent of patients that take them (statins for five years with prior heart disease where one in thirty-nine was helped). Most of the effects are much less than that.

Contrast this to Willis' et al. study that has enough of an effect to show a remarkable landmark result with far, far fewer participants. The NNT in his study was less than two, and this was on a relatively small dose of therapy with no ability to adjust the dose as needed. That means in this preliminary trial, 60 percent of patients benefited versus the 2.5 percent of the most effective medicines in the drug trials. With easily obtainable serial surrogate indicators of progress, stabilisation or regression, therapy can be adjusted to ensure a NNT of nearly one as has been stated and observed by Bush [19,57].

Current therapy fails to address the silent nature of heart disease and it remains the number-one killer. Screening tests lack sensitivity and specificity; diagnostic tests are expensive, toxic, dangerous and cumbersome and therapies are essentially without important effect and with significant toxicities [58]. Thus have we dealt with the biggest challenge of our time in medicine. Beyond this, the mechanism of action of these medications, the cholesterol-lowering ones in particular, is simply to stop the normal healing process of the endothelium without providing it other options as the literature quoted in this article demonstrates.

Yet, in the background, many scientists have labored with academic rigor and a passionate search for the cause, effect and legitimate therapy for atherosclerosis. And, they have done it. Willis, Klenner, Cathcart, Stone, Pauling, Rath, Levy, Huggins, Bush and many others throughout the world have worked tirelessly to bring the knowledge of the solution to this biggest problem to the forefront of medicine. Bush has ushered in a new era of medicine, and added a touch to these great works by giving us the ability to monitor patients' progress and to ensure the best possible outcome on an individual basis. These scientists and doctors have brought us to where it is now possible to live free of the problems related to vascular disease and the shortened lives, the broken families from sudden, unnatural loss and the burgeoning disability. A new era is envisioned in which practitioners now have the ability to address the cause and treat accordingly for these many illnesses. Patients will thrive with a cost-effective, non-invasive, non-toxic approach to vascular health.

CardioRetinometry ${ }^{\circledR}$ provides us this opportunity for optimal health and life extension. Many more studies are to be done validating this work further, but this should not delay the ability of patients to improve immediately. Rather than working strictly from a protocol and an educated guess as to what therapy might best suit a patient, each individual patient can be monitored easily on an ongoing basis. This is especially important as any given patient may have risk factors, seen or unseen, that increase oxidative stress and deplete Vitamin C, leading to a rationing in the body and a potential focal scurvy. Levy discusses many of these in his book, Stop America's \# 1 Killer, and includes many factors that can vary and dramatically change a person's demand for Vitamin C. There is much overlap with the factors that Bush has observed to cause an increased demand for Vitamin C.

As one can see, these varying factors can produce a varying degree of oxidative stress requiring a varying degree of Vitamin $\mathrm{C}$ to neutralise. This is why Bush recommends the use of easily obtainable, non toxic, inexpensive and extremely accurate serial monitoring with direct visualisation under hyper-magnification of the vascular status of the retinal vessels, correlating particularly with the coronary arteries (as it has been shown to be a nearly perfect surrogate indicator of the coronary arteries by Michelson et al. and Tedeschi-Reiner et al. and the vascular status of the body in general). These images can be alternately rapidly flickered in overlap to accentuate even the smallest photo-micrographic changes.

Bush recommends ongoing monitoring for a year or more until the plaque is visualized to be regressing in a consistent fashion and vascular symptoms subside, then following on a per six-month basis from that point forward. This way a progression of atherosclerosis due to any factor that has caused an increase in oxidative stress can be caught early and the program can be adjusted as necessary. This is a major advance over anything that has been possible up until his discovery of regressing atheromas on fundoscopic photography in 1999 and his subsequent years of refining this new science. It is an improvement on the currently available screening and diagnostic methods in the following ways: 
a) CardioRetinometry® is sensitive 100 percent compared to angiogram

b) It is specific: 96 percent compared to angiogram

c) Highly magnified to get a picture of small vessels

d) Can detect a one percent change in progression/regression of atherosclerosis

e) Is inexpensive

f) Has no toxicity

g) Can be repeated as often as necessary

h) Is not invasive

\section{i) Offers true prevention}

Due to the high stakes of a vascular event, and the high variability of oxidative stress on the patient's need for therapy, it is also recommended that patients register with a practitioner to be followed for life. It has been noted that discontinuing therapy can lead to a progression of atherosclerosis in a short amount of time, and this is to be avoided with continuity and caught early so intervention can continue. Should a registrant change practitioners, this would be done with a formal hand-off from one practitioner of CardioRetinometry ${ }^{\circledR}$ to the next to ensure a smooth transition, continuity and to prevent the registrant falling through the cracks. The practitioner would have a duty to ensure close follow up and monitoring, to advise and educate the registrant. As such, the practitioner of CardioRetinometry ${ }^{\circledR}$ is forbidden, by the Institute of CardioRetinometry $\AA$, to carry or sell required supplementation to prevent a conflict of interest, real or apparent, from interfering with the goal of optimal registrant outcomes.

As of this writing, individuals who smoke cigarettes may not register for treatment with Cardio Retinometry ${ }^{\circledR}$ as smoking all but reverses the effects of any supplementation that could help their vascular status [59]. They are encouraged to quit smoking and can be referred for aggressive smoking intervention. Should they quit, then registration and intervention with CardioRetinometry ${ }^{\circledR}$ may take place.

In the near future, all practitioners will be able to reverse and prevent heart attack, stroke and multiple other complications of atherosclerosis. A whole new field of research is open with increasing technology making fundoscopic photomicrography with higher resolution available to detect very nuanced improvements or worsening of each patient's vascular status. Contrast this to the statement made in 2014 in the journal Atherosclerosis.

Research to identify and evaluate new atherosclerosis treatments is challenging. Despite best efforts, only a handful of drugs has been proven to reduce atherosclerotic events. The ultimate step in drug evaluation (phase 3 trials) is to assess impact on clinical end points. Because of the nature of the disease, phase 3 atherosclerosis drug trials require enrollment of large numbers of patients (at times $>20,000$ ) and long follow-up periods, with typical costs exceeding $\$ 350$ million.
Such end points could be monitored much more easily and inexpensively than the multiple modalities that are discussed in the above article. CardioRetinometry® has distinct advantages over each of them. Unfortunately, any medication that requires tens and thousands of patients to show an effect is going to have a very high number needed to treat (NNT). It is the thought of this author that therapies should be looked at that have a much smaller NNT with the goal being one to two. This would also greatly lower the cost of research. Preliminary studies and reports seem to indicate that this is possible if the correct etiology and pathophysiology of atherosclerosis is considered [60].

\section{Conclusion}

There is sufficient evidence in the peer-reviewed scientific literature to substantiate the use of CardioRetinometry®. In addition, CardioRetinometry® would lend itself well to large clinical trials should enough practitioners be trained in it. Even so, it is clear from the work of several dedicated scientists that atherosclerosis is reversible with Vitamin C, lysine and proline. Dr. Sydney Bush, from the UK, has added the crucial touch of being able to monitor this improvement to ensure its occurrence in each registrant and to modify therapy as necessary. This addition brings us into a new era of medicine. Dr. Bush now brings to the world the most direct route to the prevention and reversal of coronary artery disease and stroke as well as the many complications of atherosclerosis, including:
I. Abdominal Aortic Aneurysm
II. Dissecting Aortic Aneurysm
III. Cerebral Aneurysm
IV. Claudication

V. Macular Degeneration

VI. Central Artery Occlusive Blindness

VII. Mesenteric Ischemia

VIII. Congestive Heart Failure

IX. Transient Ischemic Attack

X. Peripheral Artery Disease

XI. Heart Valve Stenosis

XII. Heart Valve Regurgitation

XIII. Atrial Fibrillation

\section{Raynaud's Phenomenon}

\section{Erectile Dysfunction}

Hollenhorst first noted that the "normal healthy" light reflex of retinal vessels was in fact plaque and emboli in 1961[18]. Michelson et al found that it indicated coronary artery disease [20]. Michelson concluded, referring to these reflexes, "Abnormal light reflexes were the most sensitive indicator of the presence and extent of coronary artery disease." These white reflexes are not at all normal, rather they are early sensitive and specific indicators of coronary atherosclerosis. All Optometry and medical 
schools now have the opportunity and invitation to begin correct education on this matter.

\section{References}

1. Willis GC, Light AW, Gow WS (1954) Serial arteriography in atherosclerosis. Can Med Assoc J 71(6): 562-568.

2. Willis G, Fishman S (1955) Ascorbic acid content of human arterial tissue. Can Med Assoc J 72(7): 500-503.

3. Furie M, Mitchell RN (2012) Plaque Attack: One Hundred Years of Atherosclerosis in The American Journal of Pathology. The American Journal of Pathology 180(6): 2184-2187.

4. Hort W (2002) History of Cardiovascular Pathology. Z Kardiol 91 Suppl 4: 20-24.

5. Gaudio E, Carpino G, Grassi M, Musca A (2006) Morphological aspects of atherosclerosis lesion: past and present. Clin Ter 157(2): 135-142.

6. Kolodgie FD, Yahagi K, Mori H, Romero ME, Trout HH, et al. (2017) High-risk carotid plaque: lessons learned from histopathology. Semin Vasc Surg 30(1): 31-43.

7. Poredos P, Poredos P, Jezovnik MK (2017) Structure of atherosclerotic plaques in different vascular territories: clinical relevance. Curr Vasc Pharmacol.

8. Panh L, Lairez O, Ruidavets JB, Galinier M, Carrié D, et al. (2017) Coronary artery calcification: From crystal to plaque rupture. J Arch Cardiovasc Dis S1875-2136(17): 30129-30138.

9. Yuhua S, Baoping W (2017) From vulnerable plaque to blood healthy therapy. Perfusion.

10. Xie Z, Hou J, Yu H, Jia H, Du H (2016) Patterns of coronary plaque progression: phasic versus gradual. A combined optical coherence tomography and intravascular ultrasound study 27(8): 658-666.

11. Sudo M, Li Y, Hiro T, Takayama T, Mitsumata M, et al. (2017) Inhibition of plaque progression and promotion of plaque stability by glucagonlike peptide-1 receptor agonist: Serial in vivo findings from iMapIVUS in Watanabe heritable hyperlipidemic rabbits. Atherosclerosis 265: 283-291.

12. Wang Z, Cho YS, Soeda T, Minami Y, Xing L, et al. (2016) Threedimensional morphological response of lipid-rich coronary plaques to statin therapy: a serial optical coherence tomography study. Coron Artery Dis 27(5): 350-356.

13. Rath M, Pauling L (1991) Solution to the Puzzle of Human Cardiovascular Disease: Its Primary Cause is Ascorbate deficiency, leading to deposition of lipoprotein (a) and fibrinogen/fibrin in the vascular wall. Journal of Orthomolecular Medicine 6: 125-134.

14. Rath M, L Pauling A (1992) A unified Theory of Human Cardiovascular Disease Leading the Way to the Abolition of this Disease as a Cause for Human Mortality. Journal of Orthomolecular Medicine 7(1): 5-15.

15. Pauling L, Rath M (1992)“A unified Theory of Human Cardiovascular Disease Leading the Way to the Abolition of this Disease as a Cause for Human Mortality." Journal of Orthomolecular Medicine 7(1): 5-15

16. Rath M, Pauling L (1990) Immunological evidence for the accumulation of lipoprotein(a) in the atherosclerotic lesion of the hypoascorbemic guinea pig. Proc Natl Acad Sci USA 87(23): 93889390.

17. Rath M, Pauling L (1990) Hypothesis: lipoprotein(a) is a surrogate for ascorbate. Proc Natl Acad Sci USA 87(16): 6204-6207.
18. Robert WH (1961) Significance of Bright Plaques in the Retinal Arterioles. Trans Am Ophthalmol Soc 59: 252-273.

19. Sydney J Bush (2010) 700 Vitamin C Secrets. Direct Print on Demand Ltd, Brixworth, UK, pp. 448.

20. Michelson, Morganroth, Nichols, MacVaugh (1979) Retinal Arteriolar Changes as an Indicator of Coronary Artery Disease. Arch Intern Med 139(10): 1139-1141.

21. Tedeschi-Reiner E, Strozzi M, Skoric B, Reiner Z (2005) Relation of atherosclerotic changes in retinal arteries to the extent of coronary artery disease. Am J Cardiol 96(8): 1107-1109.

22. Matthias R (2004) Why Animals Don't Get Heart Attacks ... But People Do!. ( $4^{\text {th }}$ edn), Rath Education Services, USA.

23. Hickey S, Roberts H (2005) Ascorbate: The Science of Vitamin C. Morrisville, USA, p. 70.

24. Padayatty SJ, Levine M (2017) Vitamin C physiology: the known and the unknown and Goldilocks. Oral Dis 22(6): 463-493.

25. Stone I (1966) On the Genetic Evolution of Scurvy. Acta Geneticae Medicae et Gemelloghiae 15: 345-350.

26. Levy T (2006) Stop America's \#1 Killer! LivOn Books, USA, p. 23-39.

27. Willis GC (1953) An experimental study of the intimal ground substance in atherosclerosis. Can Med Assoc J 69(1): 17-22.

28. Mendiratta S, Qu ZC, May JM (1998) Erythrocyte Ascorbate Recycling: Antioxidant Effects in Blood. Free Radical Biology and Medicine 24(5): 789-797.

29. https://www.cdc.gov/mmwr/volumes/66/wr/mm6615a8.htm

30. Willis GC (1957) The reversibility of atherosclerosis. Can Med Assoc J 77(2): 106-108.

31. Willis, GC (1953) "An experimental study of the intimal ground substance in atherosclerosis." Can Med Assoc J 69(1): 17-22

32. Coșkun Cevher S, Balabanli B, Aslim B (2015) Effects of probiotic supplementation on systemic and intestinal oxidant-antioxidant events in splenectomized rats. Surg Today 45(9): 1166-1172.

33. Pauling L (1986) How to Live Longer and Feel Better. Oregon State University Press, USA, p. 73.

34. Levy T (2006) Stop America's \#1 Killer, Pg 33

35. Hornig D (1975) Distribution of ascorbic acid, metabolites and analogues in man and animals. Ann NY Acad Sci 258: 103-118.

36. Moser U (1987) The uptake of ascorbic acid by leukocytes. Ann NY Acad Sci 198: 200-215.

37. https://ods.od.nih.gov/factsheets/VitaminC-HealthProfessional/

38. Rath M (2003) Why Animals Don't Get Heart Attacks... But People Do! The Health Organization, USA, p. 25.

39. Fonorow 0 (2008) Practicing Medicine Without A License? The Story of the Linus Pauling Therapy for Heart Disease. Taxmann Publications Private Limited, USA, pp. 256.

40. Levy T. (2006) Stop America's \#1 Killer, Pg 293

41. Rath M. (2003) Why Animals Don't Get Heart Attacks... But People Do! Pg. 253

42. Hickey S, Roberts H (2004) Ridiculous Dietary Allowance. Lulu.com, USA, pp. 1-151. 
43. Klenner, Frederick R (1952) The vitamin and massage treatment for acute poliomyelitis. South Med Surg 114(8): 194-197.

44. Klenner, Frederick R (1948) Virus pneumonia and its treatment with Vitamin C. South Med Surg 110(2): 36-38.

45. Klenner, Frederick R (1951) Massive doses of Vitamin C and the virus diseases. South Med Surg 114(4): 101-107.

46. Stephenson CM, Levin RD, Spector T, Lis CG (2013) Phase I clinical trial to evaluate the safety, tolerability, and pharmacokinetics of high-dose intravenous ascorbic acid in patients with advanced cancer. Cancer Chemother Pharmacol 72(1): 139-146.

47. Cameron E (1993) Vitamin C and cancer: an overview. Int J Vitam Nutr Res Suppl 23: 115-127.

48. Klenner, Frederick R (1948) "Virus pneumonia and its treatment with Vitamin C." South Med Surg 110(2): 36-38

49. Klenner, Frederick R. (1952) "The vitamin and massage treatment for acute poliomyelitis, South Med Surg 114(8): 194-197

50. Bush S (2012) 700 Vitamin C Secrets. ( $2^{\text {nd }}$ edn), Lulu.com, USA, pp. 214-402.

51. Levy T. (2006) Stop America's \#1 Killer
52. Pauling L (1986) How to Live Longer and Feel Better. Doctor yourself. com, USA, p. 71.

53. Levy T (2011) Primal Panacea. Medfox Publishing, USA, pp. 95-106.

54. https://ods.od.nih.gov/factsheets / Vita m in CHealthProfessional/\#h3

55. Kones R (2011) Primary prevention of coronary heart disease: integration of new data, evolving views, revised goals, and role of rosuvastatin in management. A comprehensive survey. Drug Des Devel Ther 5: 325-380.

56. www.thennt.com

57. Bush SJ (2017) CardioRetinometry® Reveals RarelyAbsent, Focal Scurvy, Pathognomonic of Unrecognized Ubiquitous Fatal Occult Scurvy, Unexpected Heart Attach, Thrombosis, and Stroke Deaths. eaths. J Cardiol C 8(1): 00272.

58. Tarkin JM, Dweck MR, Evans NR, Takx RA, Brown AJ, et al. (2016) Imaging atherosclerosis. Circ Res 118(4): 750-769.

59. Levy T (2006) Stop America's \#1 Killer, pg 147-154

60. Cathcart RF (1981) Vitamin C, Titrating to Bowel Tolerance, Anascorbemia and Acute Induced Scurvy. Medical Hypothesis 7(11): 1359-1376. 